\title{
Standing to Preach, Moving to Teach: What TAs Learned from Teaching in Flexible and Less-Flexible Spaces
}

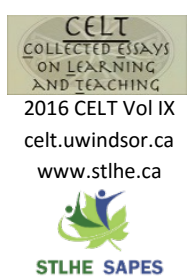

\author{
Victoria Chen, Andy Leger, and Annie Riel \\ Queen's University
}

This paper examines the effect of the architectural layout of two classrooms (one flexible and one less-flexible) on Teaching Assistants' (TAs) movement and interactions with students. Four TAs from a first-year undergraduate introductory course were chosen for the two studies. In study 1, the TAs taught the same lesson twice to two groups of students on the same day but in different classrooms, thereby controlling for content differences. Study 2 investigated the impacts that flexible and non-flexible spaces have on the same cohort of students, as the TAs continued to teach the same students but the students switched classrooms for the second half of the course, thereby controlling for differences in student participants. From the video analyses, there was a clear difference in how the TAs moved in the classroom and the interactions they had with students. Both TAs and students reported in surveys that there was a difference in their movement in the respective rooms that had an impact on their teaching and learning quality. This finding starts the conversation on how space can affect TAs, in order for TAs to consider how their movement is affected by classroom configurations, and how this change in movement can affect teaching strategies and impact their students' learning.

\section{Introduction}

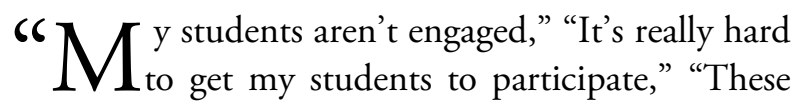
students think tutorials are a waste of time," "No one answers the questions I ask," "I think my students are asleep," are all things we have heard teaching assistants (TAs) say time and time again. Some TAs default to lecturing, delivering all the content students need to know for the tutorial or seminar in a simple and less painful manner of transmitting information. Other TAs, perhaps considered the brave ones, continue to try and engage their students in discussions, with some resorting to playing jeopardy games with tempting prizes such as candy to entice students to participate. Neither approach is necessarily incorrect, but both approaches place the TA as the authority figure stationed at the front of the room, driving what is important for students to know and dictating the path students should be taking to reach the objectives of the session. Yet, tutorials and seminars offer a different structure, and are meant for students to truly engage in what they learned from lectures and readings by being able to reflect on the new knowledge, discuss with peers, ask questions to the TA, and connect all the information together to form their own understanding. The teaching approaches previously mentioned do not allow for the described objectives of tutorials and seminars to occur, and perhaps some unconventional changes need to take place; for instance, changing the TA's physical position in the classroom.

What if the physical position of the TA were to change? What if the TA walked around the room or was seated in a physically equivalent position to the students in the class? There is an art to moving in the classroom which graduate students may not consider 
when planning their tutorials or seminars, yet doing so could help reduce many problems graduate students face during teaching that are similar to problems faculty members commonly encounter such as lack of student engagement, participation, attendance, and critical thinking. (Brooks, 2011; Cotner, Loper, Walker, \& Brooks, 2013). Students can also move around to form small and large groups, allowing the TA to more easily address students' needs.

Although this is a great idea, it may be difficult or even impossible to do because of the inflexibility of furniture configuration in the classrooms. In recent years, universities and colleges across North America have sought to change the ambiance of classrooms by implementing innovative reconfigured layouts and furniture aimed at improving the learning experience for students referred to as Active Learning Classrooms (ALC) (Baepler, Brooks, \& Walker, 2014). The common features of ALC are round tables, moveable chairs, and ample technology (SCALE-UP site, 2011), but another version, as shown in Figure 1, extends the notion of flexibility even further with no fixed furniture and white boards across the walls. For the purposes of clarification in this paper, the classroom depicted in Figure 1 will be called the "flexible space".

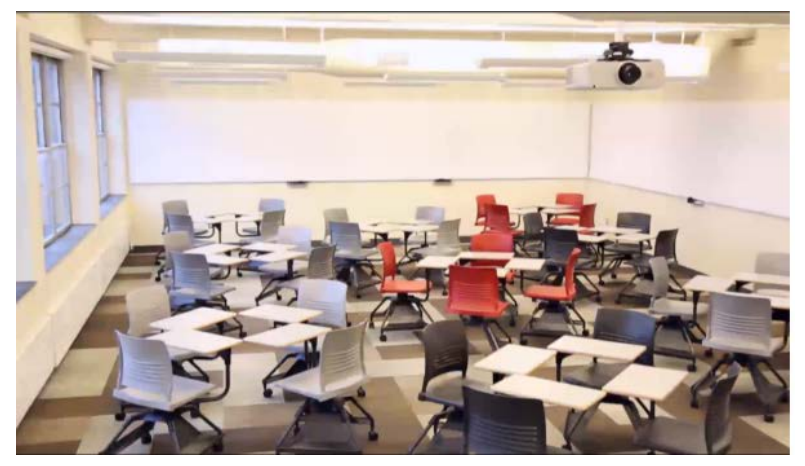

Figure 1

Flexible Space

Studies on ALCs in general have shown that, compared to the traditional lecture hall, students' satisfaction with learning was higher in Active Learning Classrooms, students' attendance in class increased, and instructors reported being able to engage and interact with students in ways that were not possible in the traditional classroom layout (Brooks, 2011; Cotner, et al., 2013). One common aspect of most of these studies is that the instructors are experienced teachers and have some experience in assuming the facilitator role in teaching (HmeloSilver \& Barrows, 2006). However, it remains unclear how novice instructors such as first time TAs would react and use these new learning spaces. Furthermore, in most studies, the comparison of the traditional classroom is conducted retrospectively, and the content of the course could be a factor contributing to how instructors move and the degree of interaction with students in one classroom compared to another. The current paper aims to address these confounding factors with two studies. In study 1, TAs taught the same session twice on the same day in two different rooms, thereby eliminating the confound of different course content. In study 2, students in the classes switched rooms half way through the year, thereby eliminating confounds of student participant differences.

Before examining the findings from the studies, take a moment and think about being in the spaces in Figure 2. What teaching strategies would you use in the two spaces? How would you configure students in these space? Would they be the same? Different? Why would they be the same or different?

\section{Study 1}

\section{Research Questions}

1a) What are the Teaching Assistants' (TAs) initial impressions of teaching in these two different spaces? 1b) Are there differences in TAs' movement and interactions with students in these two spaces?

1c) What are the TAs' thoughts on their movement and interactions with students in these two spaces after the first term?

1d) What are the students' thoughts on movement and learning in their respective assigned space after the first term? 

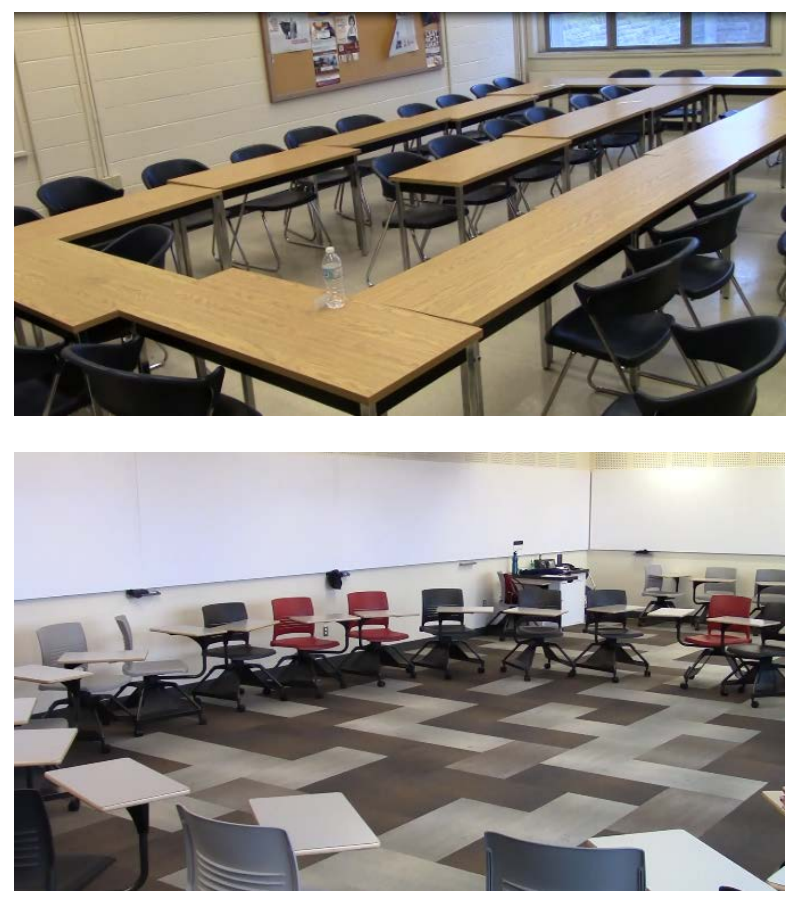

Figure 2

Traditional less-flexible space vs flexible space

\section{Participants}

Four TAs from a first year undergraduate studies course were chosen to take part in the study. The TAs taught the same session twice in one day with two different groups of students in different classrooms (one in a less-flexible classroom and another in a flexible space), thereby controlling for content differences. Two of these TAs taught in less-flexible space first and flexible space immediately after, while the other two TAs taught in the reversed order, thereby controlling for order effects. Students from their sessions were given a survey at the end of the first term. Participation was completely voluntary, and this research project has received ethics approval through the university's Human Research Ethics Board.

\section{Data Source}

\section{Informal discussions}

Three weeks into the term, the research team engaged in brief conversations with each of the TAs, obtaining their initial impressions teaching in the two spaces. The conversation aimed to uncover the teaching approaches these TAs brought to their courses, specifically if they preferred a teacher-centered approach or student-centered approach.

\section{Videos of sessions}

Two randomly selected sessions were videotaped during the term. Each TA had two videos per session, one with students in the less-flexible room and one in the flexible room. The videos were analyzed by playing them side by side in order to see any differences.

\section{TA survey at end of first term}

The TAs were given an online survey at the end of the term to compare their teaching experiences in the two rooms through FluidSurvey. The survey contained open-ended questions; for example, "Describe your typical teaching strategies," "Compare the ease in doing the above strategies in the two rooms," "Compare the amount and quality of interactions you had with students in each room," and "Compare the ease in moving around the room." Classic content analysis (Leech \& Onwuegbuzie, 2007) was used to analyze all open-ended responses, which focuses on the number of times each code is used, helping to determine which concepts are important to the participants.

\section{Student survey at end of first term}

The students were also given an online survey at the end of the term asking them to rate their experience in the particular classroom with the emphasis on different aspects of movement, such as their ability to form groups, shift into whole class discussions, and move to face the TA and other students. Students rated 12 items on a scale from 1 - difficult to 10-easy (Cronbach's Alpha $=.94)$. Open-ended questions followed, inquiring about what they liked most and least about the rooms and how it affected their learning. Classic content analysis was used to analyze the open-ended responses. 


\section{Findings}

\section{Informal discussions}

All four TAs engaged in informal discussions with the research team throughout the term, three of which completed the survey at the end of the first term.

\section{TA's pedagogical beliefs at the start of the term}

During the first filming session, we asked each TA how they felt their teaching was going for the first few weeks of the term and what it was like to teach in the two different spaces. Interestingly, the TAs pedagogical beliefs seemed to greatly influence their preference in space at the start of the term. TAs who described their teaching strategies as "little-lecturing" and "mostly discussion based" stated they immediately preferred the flexible room after the first session. They were able to join groups and interact with students quickly and easily. These TAs seemed to embody the facilitator role or student-centered teaching approach in their seminars.

The other TAs who reported their teaching approach as more lecture-based and "teacher-centred" did not like the flexible space at first, describing the space as cluttered and confusing with no focal point. These TAs found it difficult to get students attention after they broke off into small groups because they were engaged in their conversations. As one TA stated, she preferred the less-flexible space because it was more reminiscent of her experience as an undergraduate student at a different university. The less-flexible room was more comfortable and familiar for her, as there was a single focal point in the room which was at the front of the room with the blackboard allowing her to teach.

\section{Videos}

Since the videos were played side by side, the sound was removed and analysis focused on the actions of TAs and students. Particular attention was given to where the TA positioned him/herself for most of the class, and how the TA moved in the classroom.

\section{TAs' position in the room}

There was a clear difference in where TAs spent most of their time in the classroom. In the flexible space, some TAs sat near the white board at the start of class, while other TAs sat on the other side of the classroom facing the whiteboard. The TAs were nearly indistinguishable from the students in the video, removing the physical hierarchy between instructor and students. After taking attendance and doing a brief introduction, students split into small groups, and the TAs would quickly join a group to engage in discussion with them.

In the less flexible room, all the TAs started the class standing at the front of the room at the podium near the black board. Interestingly, TAs spent more time talking at the start of class in this room than they did in the flexible room, in some cases almost double the amount of time. There were more individual student questions from sessions in the lessflexible room, with the TA responding to one student at a time while everyone else sat and listened. In the flexible room, TAs had students go into groups more quickly and answered questions as they went around to each group. Screenshots from the videos depicting the difference in the position of TAs' at the same point in time during the sessions are shown in Figure 3. TAs walked around quicker and more frequently in the flexible rooms, and in some instances were even able to attend to groups more than once. Some TAs moved seamlessly to the next group in their chairs with wheels; these tended to be ones who identified themselves as having a "student-centered" approach to teaching. Other TAs got up and walked to the next group and found an empty chair to sit with the group; these tended to be TAs who identified as having a "teacher-centered" approach.

In the less-flexible space, all TAs tended to stay at the front of the room, sitting or standing at the podium or a desk (see Figure 4 for comparisons). There were more physical barriers that prevented TAs from reaching each group in this space, with large tables and students blocking the path to other groups. The TAs seemed more isolated in the less-flexible space, sitting alone at their seat and going through paper work or standing at the podium. This did not 


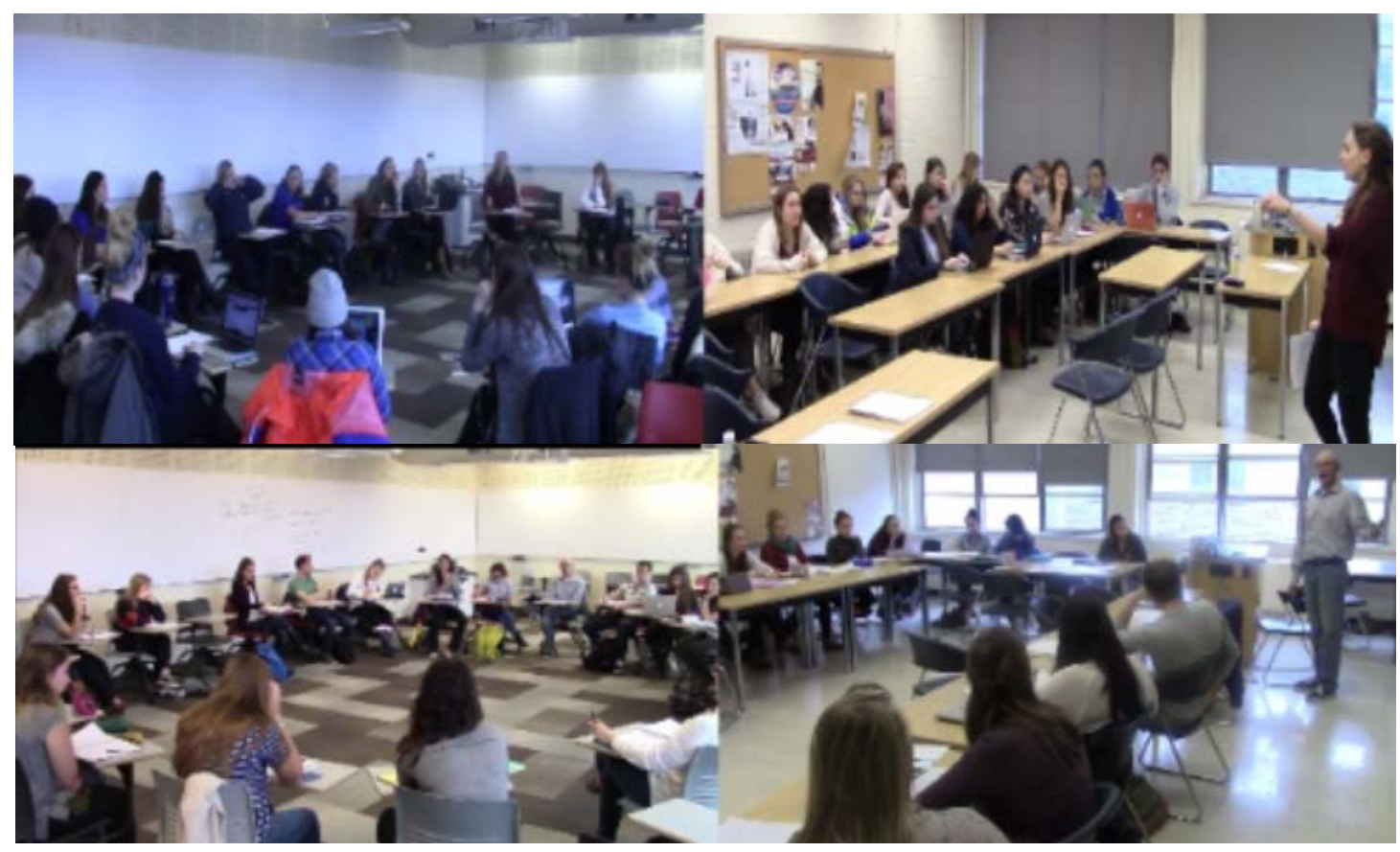

Figure 3

Screenshots of video of the same two TAs (top vs bottom) in the flexible (left) and less flexible (right) room at the same point in time during the class session

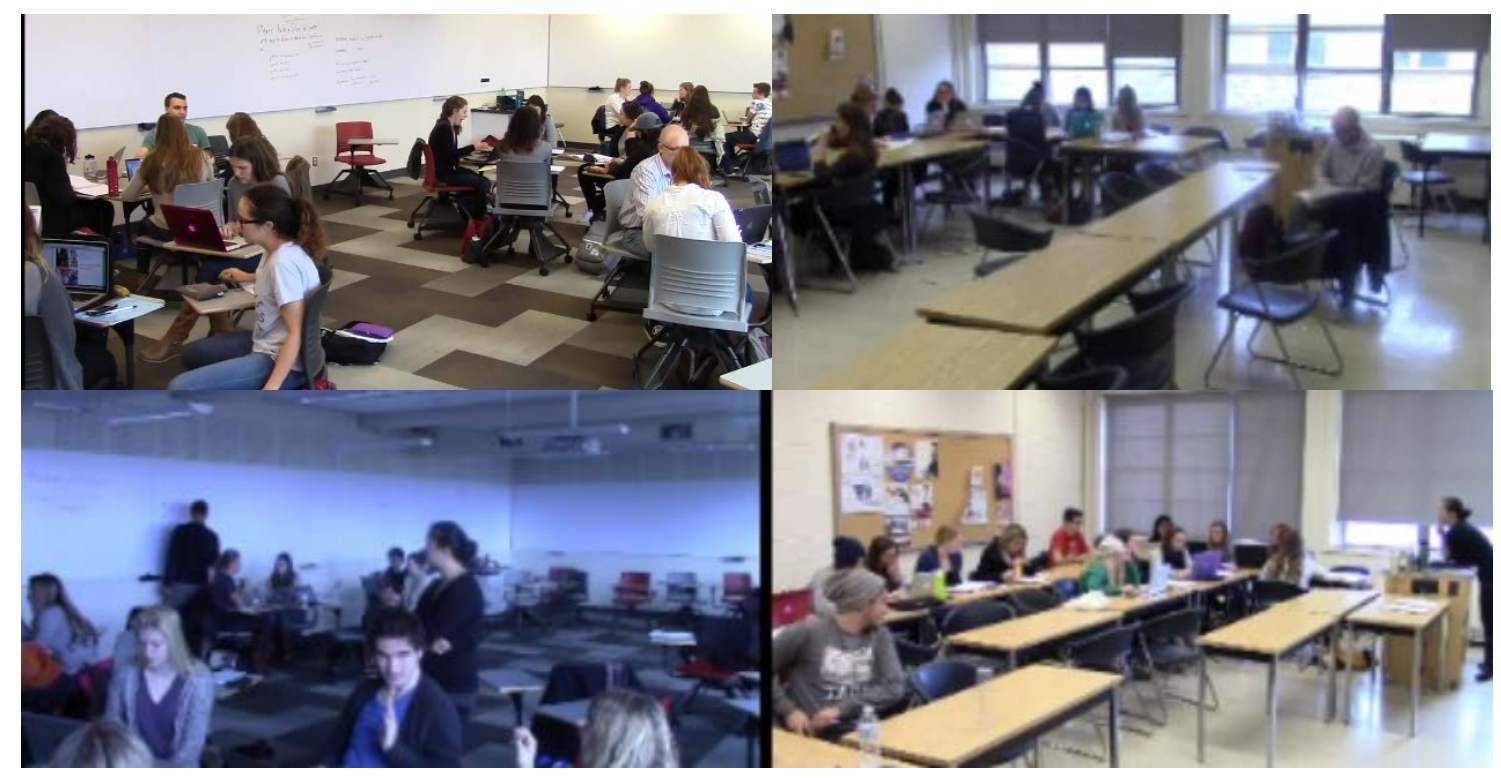

Figure 4

Group work in flexible (left) and less flexible (right) classrooms 
occur as frequently in the flexible space, with TAs only returning to their seat for a drink and immediately going to another group that required their attention.

\section{Survey responses}

At the end of the first term, the TAs were emailed an online survey with open-ended questions; three out of four responded. A summary of the findings is shown in Table 1. Overall, the three TAs described the flexible room as the better room in which to teach and claimed it elicited better student responses. The TAs shared very similar teaching strategies, including large class discussions, small group discussions, small group brainstorm periods, and micro lectures with question and answer periods. All three attributed their positive experiences in the flexible room to the "freedom to move around the classroom".

\section{Interactions and movement}

The combination of the larger space and smaller chairs/desks in the flexible room allowed movement to again be much easier than in the less-flexible room. TAs reported no obstacles to interacting with students in the flexible room. They were able to easily reach each group without any problems. Additionally, being able to see all the students clearly in the flexible space made interactions effortless and occur seamlessly.

In the less-flexible space, the TAs described the room as appearing smaller because the desks were so large, causing physical barriers to reach each group. Moreover, there would be areas in the classroom with blocked sightlines (e.g., one student sitting behind other students), causing these students to more easily exclude themselves from the discussions. One TA expressed that it was particularly difficult to get these excluded students to be part of the conversation.

\section{Student surveys}

Forty-six students responded to the questionnaire ( $N$ $=24$ in less-flexible space, $N=22$ in flexible space). The sum of the 12 items created the variable for movement in the classroom. An independent t-test was used to compare their responses on ease of movement. Students in the flexible room $(M=94.45$, $S D=16.61)$ rated the room as a significantly better space for movement than students in the less-flexible space $(M=66.04, S D=24.99, t(44)=4.49, p<.001)$.

\section{Movement and sightlines}

In the open-ended responses, students in the flexible classroom unanimously agreed they loved the space. Many students compared the experience with their tutorials in other courses, wishing all tutorials were held in this space. A few representative quotes include: "Much better learning environment overall than the average classroom," "Everything about this room is perfect and it brings me to tears. If this was my tutorial classroom for all my classes, I would have a stronger work ethic, and enjoy class discussions," "I cannot stress enough that this is ultimately the best tutorial room at the university. My marks have skyrocketed in this course, and it is my favourite class this year because it is such a welcoming, warm and clean environment. Please try to make more rooms like this, and I will make it to the dean's honours list."

Students described the ease in shifting from whole class discussions into small groups and back to whole class discussions: "It's easy to do group work because students can physically separate themselves and break off into groups, " and "it is an easy and efficient way to get into groups and have discussions whenever." Similarly, the importance of being able to see group members was repeated by students in the flexible classroom: "I could see people in my group easily and I felt integrated in the class. I actually made friends in this class." Students commented on how the space and freedom to move around the room encouraged them to participate more often, as one student stated,

I wanted to participate more, and it automatically made me much more aware, and awake during tutorials in comparison to other tutorials where I sit at a solid desk. It helped allow interaction among students, as well as the white boards were very beneficial in allowing collaborative brainstorming amongst group members. 


\section{Table 1}

Summary of TA responses indicating which space provided better quality or no difference for the listed characteristics

\begin{tabular}{lccc}
\hline & $\begin{array}{c}\text { Enact typical teaching } \\
\text { strategies }\end{array}$ & $\begin{array}{c}\text { Amount and quality of } \\
\text { interactions }\end{array}$ & $\begin{array}{c}\text { Ease in moving around room to } \\
\text { attend to students }\end{array}$ \\
\hline Less-flexible & 0 & 0 & 0 \\
Flexible & 3 & 3 & 3 \\
No difference & 0 & 0 & 0 \\
\hline
\end{tabular}

In the final comments section, most students pleaded to not be moved into the traditional, less-flexible class for the next semester.

A drastically different response was given by students in the less-flexible class, with the majority describing the space as a typical classroom similar to their other tutorial classes. All the students agreed movement was difficult and often impossible in the small, tight space. One student reported, "It was not easy to get around or find a seat without bugging a bunch of people." The restricted feeling was reiterated by several students with similar quotes, such as this one: "It is very cramped and is almost impossible to walk along the back wall when people are there." Another student described problems with the inflexible layout: "The lay out of the desks was either kept in a standard forward direction or arranged into a circle. The circle was great for class discussion but made the room feel hard to move in and cut off from others besides those directly beside me."

About half the responses mentioned feeling "cut off" from whole-class discussions, attributing the problem to sightlines in the room. Some students who sat behind others or in the corner of the room found it difficult to see the TA and hear other students, especially when they were in sitting in small groups. The shift from small group to class discussion was difficult, as one student commented, "It is difficult to balance doing group work and having a class discussion."

\section{Discussion}

Based on the findings from study 1 , it is clear that there was a difference in the TA's movement between the two spaces, and this impacted their teaching approach and students' perceived learning. To answer question 1a) and $1 \mathrm{~b}$ ), the TAs began the term with different impressions of the flexible space. Some loved the flexible space, as it suited their "student-centered" teaching approach, while others disliked the flexible space, because it did not align with their "teachercentered" approach. This was reflected in the videotaped sessions, where TAs who embodied the "student-centered" approach stayed in one chair and moved effortlessly from one group to the next, joining in different groups' conversations. TAs who embodied the "teacher-centered" approach tended to walk around the classroom, unsure of whether to join unless they found an available chair to use.

Interestingly, in the less-flexible space, all TAs took on a more "teacher-centered" approach, with everyone starting the class by standing at the podium and leading the class for a longer period of time than when they were in the flexible space. It could be interpreted that the less-flexible space more rigidly defined the TAs' roles as the leaders and lecturers, while in the flexible space, the space defined the TAs' roles as facilitators, who occupied a physically equivalent position to that of the students. 
This latter role seemed to be uncomfortable for some TAs at the start of the semester.

To answer question 1c), the surveys at the end of the first semester revealed all three TAs who responded indicated that the flexible space better enabled their teaching strategies, and improved the quality of the interactions with their students in this classroom, because they were able to physically get to students and had better sightlines in this space. Even a TA who initially disliked the flexible space became comfortable after being in the room for a semester. The space and flexible configurations changed the TA's perception of the room.

The findings for question 1d) are reflective of the responses to 1c), as students' responses mirrored these reactions from the TAs. The students in the flexible space had very positive reactions. They tended to focus on working with other peers and fostering relationships with other students, an aspect that was drastically different from their experiences in other tutorials. The sightlines they described indicated a better ability to see other students during class discussions and to see the TAs. Students in the lessflexible room, on the other hand, emphasized the difficulty in being able to see the TA, and felt disconnected from the whole-class discussions. This contrast may suggest that when TAs were in the flexible room, they embodied more of a facilitator role and student-centered approach to teaching, and became less of the focus in the sessions.

Even though content was controlled, the direct causal link between space and teaching cannot be made because the students in the sections were different. Differences in engagement, interactions, and quality of work could be due to individual student differences. As one TA put it in the survey, "I don't know if the differences is [sic] because of the group or the room since I have not taught these students elsewhere." Consequently, the next study examined the same group of students switching spaces.

\section{Study 2}

\section{Research Questions}

2a) Having experienced teaching the same group of students in both rooms, what are the Teaching Assistants' (TAs') thoughts on space impacting their movement and teaching after the second term?

2b) Likewise, what are the thoughts of students on space impacting their movement and learning after having tutorials in both spaces?

\section{Participants}

The same four TAs from study 1 continued to teach the same students in the second half of the course, but this time the students switched classrooms. Those who were in the less-flexible space were now in the flexible space, and vice versa, thereby controlling for differences among student participants. Both TAs and students from the sessions were given a survey at the end of the course.

\section{Data Source}

Because the content and activities in the sessions would be different from the first term, the sessions were not recorded on video as the direct comparisons between one space to the other would be confounded by different content and activities, and likely less meaningful. Instead, surveys were given to the participants at the end of the term. The TAs received a questionnaire consisting of open-ended questions asking them to compare the same group of students in the two different rooms: "Now that you have taught the SAME groups of students in BOTH rooms, for the following sections, think about the differences between the same groups of students in the two spaces." The comparisons included commenting on: student participation, student engagement, quantity and quality of interactions, and quality of work produced. Additionally, TAs were asked to consider what they learned from the experience in teaching in the two different spaces with 
regard to their approach to teaching, interest in teaching, and what they will apply to their future teaching.

Students were given a survey similar to what they completed in study 1 . They rated their experience in movement in the second classroom on a scale from 1-difficult to 10- easy. The open-ended questions on this survey asked students to make comparisons between the two rooms. Classic content analysis was used to identify themes from the openended responses.

\section{Findings}

\section{Survey responses}

At the end of the second term, the TAs were emailed an online survey with open-ended questions, and all four TAs responded. A summary of the findings is shown in Table 2. Similar to study 1 , the TAs described overwhelmingly better experiences in teaching and in students' learning in the flexible space with the same groups of students. As one TA responded, "There's no comparison. [The flexible space] is more conducive to the quality of interactions with students in every way." Surprisingly, compared to study 1, the responses focused on the TA's own actions and movements in the room and how this affected the students' learning. The next section provides a more in-depth discussion on two themes identified from their responses: TA's position in the classroom and what the TAs learned from teaching in the two rooms.

\section{TA's position in the classroom}

The TAs reported that they moved differently in these two rooms, attending to students more in the flexible room than in the less-flexible room. There was a tendency to stand at the front in the less-flexible room, and the TAs attributed this to the space, not the dynamics with the students. One TA stated, "I was more likely to encourage group activities/discussions/work with the white board [in the flexible room], as opposed to standing at the front lecturing/ writing on the chalkboard [in the lessflexible room]. The limited movement in [the less- flexible room] undermined the quality of students' work." Another TA stated, "[The less-flexible room] had the effect of positioning some students behind others and forced me to stand in front of the class, which limited eye contact and so forth. Students were not as actively engaged in this room." There was more awareness on the TA's part of their actions in the room and how it impacted the dynamics of the same group of students: "[The flexible room] was more conducive to quality of interactions I had with students in every way. There was a difference."

\section{What the TAs learned from teaching in the two rooms}

The teaching experience in both rooms led TAs to be more aware of the impact space has on their teaching approaches and students' learning. Some TAs noted changing the arrangement of desks in the second term because they saw the impact spatial configuration can have on the quality of small and large group discussions. Some TAs who had planned micro lectures and large class discussions changed these into small group discussions because they saw how conducive they were to producing effective student learning. Furthermore, two of the TAs even suggested to instructors in other courses in which they assist to have tutorials occur in the flexible room, emphasizing the impact space had on their teaching.

\section{Students' survey}

Twenty-one students responded to the questionnaire. The sum of the 12 items created the variable for movement in the classroom. An independent t-test was used to compare their responses on ease of movement in the space in the second term. Students in the flexible room $(M=88.22, S D=32.95)$ rated the room as a significantly better space for movement than the less-flexible space $(M=44.00, S D=$ $30.70, t(19)=3.17, p=.005)$. When comparing their experiences in both rooms, 20 out of the 21 students chose the flexible space as the space in which they would want to have future tutorials. Student comments emphasized the relaxed and comforting feeling they had in the flexible space. Being able to move around, brain storm on the white boards, and 
Table 2

Summary of TA responses indicating whether or not the space improved the quality of the listed characteristics

\begin{tabular}{lcccc}
\hline & $\begin{array}{c}\text { Student } \\
\text { Participation }\end{array}$ & $\begin{array}{c}\text { Student } \\
\text { Engagement }\end{array}$ & $\begin{array}{c}\text { Amount and } \\
\text { Quality of } \\
\text { Interactions }\end{array}$ & $\begin{array}{c}\text { Quality of work } \\
\text { produced }\end{array}$ \\
\hline Less-flexible & 0 & 0 & 1 & 0 \\
Flexible & 3 & 4 & 3 & 4 \\
Quality & 1 & 0 & 0 & 0 \\
unaffected & & & & \\
\hline
\end{tabular}

easily form small and large groups, were all elements that made the flexible better than the less flexible space. Students who went from the flexible space to the less-flexible space emphasized the difficulty in moving and interacting with other students, expressing their dismay that they could not remain in the same space all term: "I would highly recommend the movable room for tutorials," and "I've done so much better in [the flexible space] with the swivel chairs/desks, nobody should ever use the traditional room when compared to the new one!" The one student who preferred the less-flexible space indicated the reason was the classroom size. The less-flexible space was smaller and it was easier to hear other students compared to the larger flexible space. The student suggested taking the same elements of the flexible space and including them in a smaller-sized room for the ideal classroom.

\section{Discussion}

The experience of having the same group of students in both rooms seemed to elicit more reflective responses from TAs regarding how their teaching approaches influence students' learning compared to the response in study 1 . The attribution of space impacting teaching and learning was made more confidently by the TAs, and the students' experiences mirrored the TAs' responses. Both TAs and students preferred the flexible space because they perceived it to improve learning, and, perhaps most importantly, acknowledged the enormous influence space has on their actions while teaching and learning.

\section{Conclusions from the Studies and Implications}

It can be concluded from studies 1 and 2 that space can influence teaching and learning. The different configurations of the classroom enhanced or limited the TAs' ability to apply different teaching strategies, as well as students' ability to enact the different learning strategies. Study 1 examined the relationship at a more detailed level, with multiple methods used to address the questions. Study 2 reinforced the conclusions from study 1 by reducing external confounds such as individual differences among the students.

Acknowledging the strengths and limitations of spaces can help TAs develop solutions to engage their students and enhance their learning. However, not everyone will have access to flexible spaces, and it is important for TAs to re-imagine the spaces they are given and be creative with how they could use or change the space to facilitate their activities. It was interesting that both spaces had boards that students could write on, but students only used them in the flexible space where they were easily accessible. Some 
TAs mentioned that they started to rearrange the tables in the less-flexible space to try to make student groups. The empty space in the center of the lessflexible space could have provided a clear path to the boards, but this was not done. TAs and other instructors who do not have access to flexible spaces can still re-imagine their teaching space to determine what can be changed to improve teaching and learning.

\section{References}

Baepler, P., Brooks, D. C., \& Walker, J. D. (Eds.). (2014). Active learning spaces. New Directions for Teaching and Learning, 137. Hoboken, NJ: Wiley Periodicals.

Brooks, D. C. (2011). Space matters: the impact of formal learning environments on student learning. British Journal of Educational Technology 42(5), 719-726.

Cotner, S., Loper, J., Walker, J. D., \& Brooks, D. C. (2013). "It's not you, it's the room"-Are the high-tech, active learning classrooms worth it? Journal of College Science Teaching, 42(6), 82-88.

Hmelo-Silver, C. E., \& Barrows, H. S. (2006). Goals and strategies of a problem-based learning facilitator. Interdisciplinary Journal of Problem-based Learning, 1(1), 4.

Leech, N. L., \& Onwuegbuzie, A. J. (2007). An array of qualitative data analysis tools: A call for data analysis triangulation. School Psychology Quarterly 22(4), 557-584. http://dx.doi.org/ 10.1037/1045-3830.22.4.557 VIEW ITEM

SCALE-UP Site. (2013). Student-centered active learning environments with upside-down pedagogies. Retrieved from http://scaleup.nc su.edu/ VIEW ITEM

\section{Biographies}

Victoria Chen is a PhD Candidate in the Faculty of Education at Queen's University, with her dissertation focused on students' learning experiences in Active Learning Classrooms.

Andy Leger is an Educational Developer at the Centre for Teaching and Learning at Queen's University, and specializes in learning spaces.

Annie Riel is a PhD Candidate in the Department of French Studies at Queen's University, and has taught in the Active Learning Classrooms. 


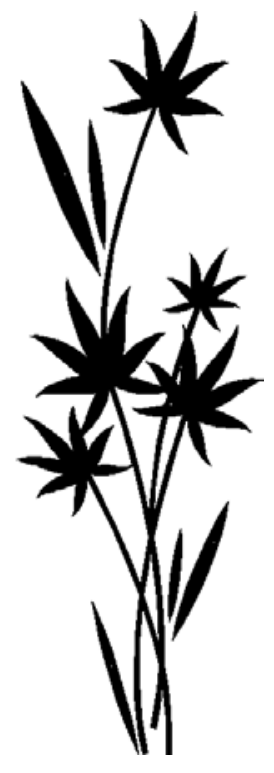

